\title{
APROXIMACIONES ACA-FAN AL UNIVERSO TRANSMEDIA DE NEIL GAIMAN: CREACIÓN Y DESARROLLO DE UN SELLO PROPIO
}

Joan Miquel ROVIRA COLLADO

(Unicómic)

José ROVIRA-COLLADO

(Universidad de Alicante)

\section{RESUMEN}

Neil Gaiman es uno de los escritores ingleses de literatura fantástica más galardonado en los últimos treinta años. Su escritura engloba tanto la novela, el relato corto, el cómic y el álbum ilustrado, radionovelas, cine o series de televisión. Desde sus primeras creaciones, como Neverwhere o Sandman, hasta las últimas adaptaciones televisivas como las series de televisión Buenos presagios o American Gods, el autor ha desarrollado un universo fantástico personal con unas características propias. Además, podemos destacar las posibilidades transmedia de sus narraciones, que se adaptan y amplían en distintos medios de expresión artística. Todo esto nos lleva a proponer el concepto de "Sello Gaiman», que incluye no solamente las obras escritas por él mismo, sino un amplio espectro de producciones donde él ha colaborado y que constituyen uno de los universos fantásticos más relevantes del siglo XXI.

Palabras clave: narrativa gráfica, narrativas transmedia, sello editorial, adaptaciones intermodales.

\section{NEIL POR SÍ MISMO}

Seguramente fue allá por 2009, cuando desde la Universidad de Alicante desarrollamos algunas actividades con la Red Internacional de Universidades Lectoras (http://universidadeslectoras.es/), que descubrimos el primer número de la revista Imaginarios (2009), que dedicaba su portada al autor inglés Neil Gaiman. Aunque ya desde la asociación Unicómic. Jornadas del cómic de la Universidad de Alicante (Rovira Collado y Rovira-Collado, 2012) llevábamos diez años dedicando unas jornadas académicas al mundo de la narración 
gráfica para reconocer su importancia en la sociedad actual, aquel número nos confirmó que se podía trabajar desde una perspectiva académica las lecturas que nos apasionaban.

En el siguiente trabajo, centrado en las relaciones entre cómic, literatura y cine y televisión que se producen a lo largo de toda la obra de Gaiman, hacemos una revisión personal, desde la perspectiva de investigadores que además son aficionados acérrimos del autor, ACA FAN, para Henry Jenkins (2006), en la que reconocemos al autor de Portchester como una figura central del imaginario fantástico desde finales de los años ochenta. Solamente hace falta visitar su web personal para revisar la infinidad de premios y reconocimientos que ha recibido y sigue recibiendo por toda su obra en las distintas vertientes de la misma.

Nuestra investigación se centra en definir un sello propio en toda la obra de Gaiman, y se realiza un análisis de esta en distintas secciones donde se analizan estas relaciones multimodales (Kress y Van Leeuwen, 2001) entre escritura, cómic y cine (García, 2013), para finalizar con una reflexión acerca de los productos más recientes o futuros, ya sean literarios, cinematográficos y de narrativa gráfica. Al ser tanta la amplitud de la obra, además de las referencias bibliográficas se ha decidido acompañar nuestra investigación con múltiples referencias digitales a noticias sobre la obra de Gaiman. Aunque no todas sus obras tengan un diseño transmedia entre distintos soportes y lenguajes, partiremos de los planteamientos del citado Jenkins (2003 y 2008), ampliados por Scolari (2013), para analizar estas historias que fluyen entre distintas plataformas.

En la propia web del autor podemos ver clasificada toda su producción artística en seis categorías: Audio, Libros, Cómics, Películas, Televisión y Teatro.

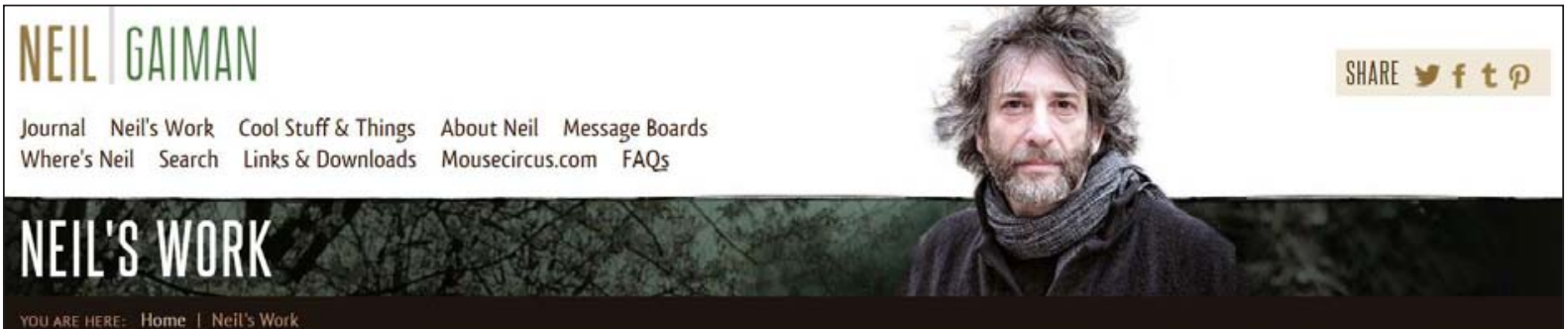

Bestselling author Neil Gaiman has long been one of the top writers in comics, and also writes books for readers of all ages. He is listed in the Dictionary of Literary Biography as one of the top ten living post-modern writers, and is a prolific creator of works of prose, poetry, film, journalism, comics, song lyrics, and drama,

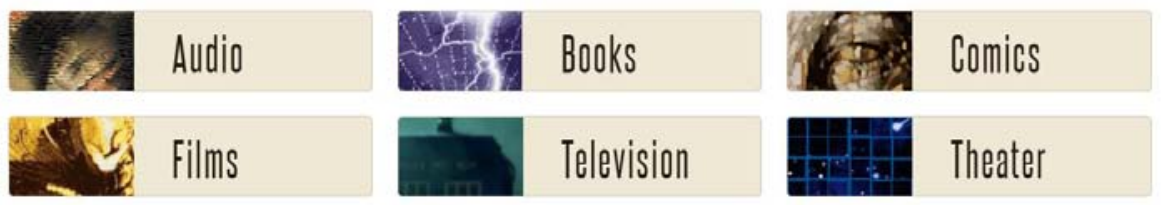

Figura 1. Producción artística de Neil Gaiman. Fuente: https://www.neilgaiman.com/works/

El objetivo principal de este trabajo, recordemos realizado desde una perspectiva personal y sin una intención de exhaustividad, ya que la inmensa obra del autor lo impide, es definir un sello personal alrededor de la obra de Gaiman. Al igual que existen universos transmedia vinculados a una franquicia específica, como Marvel (Baile López, Rovira-Collado y Vidal Martín-Toledano, 2016) o Star Wars (Rovira-Collado y Baile, 2018), podemos considerar que toda la producción de Gaiman nos ofrece un universo propio a través de distintos 
medios o formatos. Como veremos, las vertientes de la obra son muy amplias y variadas, pero desde nuestra perspectiva ya ha conseguido generar una marca personal que identifica todas las producciones artísticas donde colabora el autor. El giro transmedia del relato a través de múltiples formatos (Rodríguez, 2014) es total en este autor, porque con las últimas adaptaciones televisivas, el que fuera conocido como escritor o guionista de cómic, es ahora el productor o creador de personajes fundamentales en el imaginario actual como puede ser Sandman, el dios del sueño.

Esta intención en generar un sello propio la podemos encontrar en una de las secciones de la citada web, referida a su bibliografía.

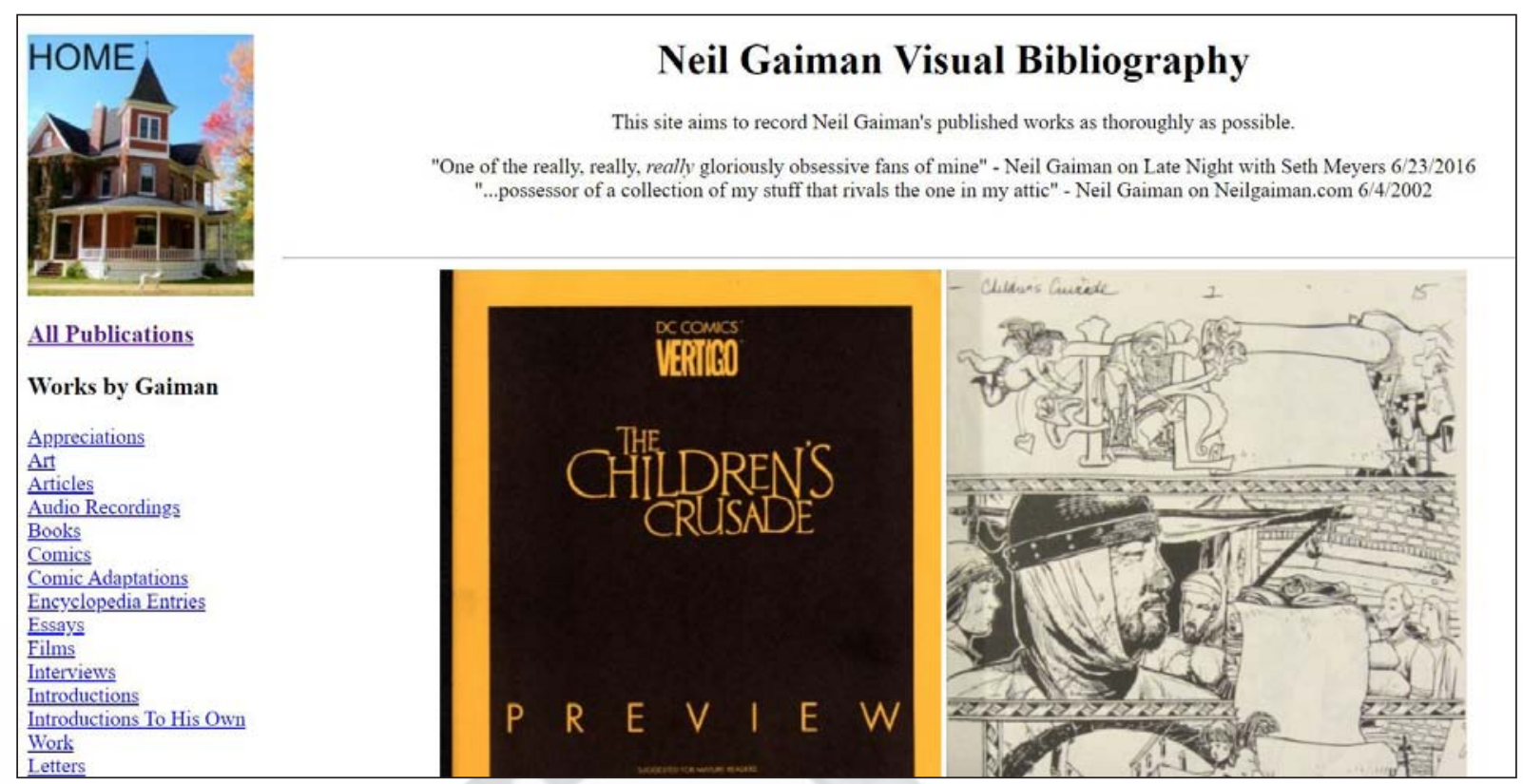

Figura 2. Bibliografía Visual de Neil Gaiman. Fuente https://www.neilgaimanbibliography.com/

En esta web podemos encontrar recopiladas gran parte de las investigaciones realizadas en torno al autor, así como distintos análisis de su obra y su arte (Campbell, 2015).

Tabla 1. Categorías de la Bibliografía de Neil Gaiman.

Fuente: https://www.neilgaimanbibliography.com/

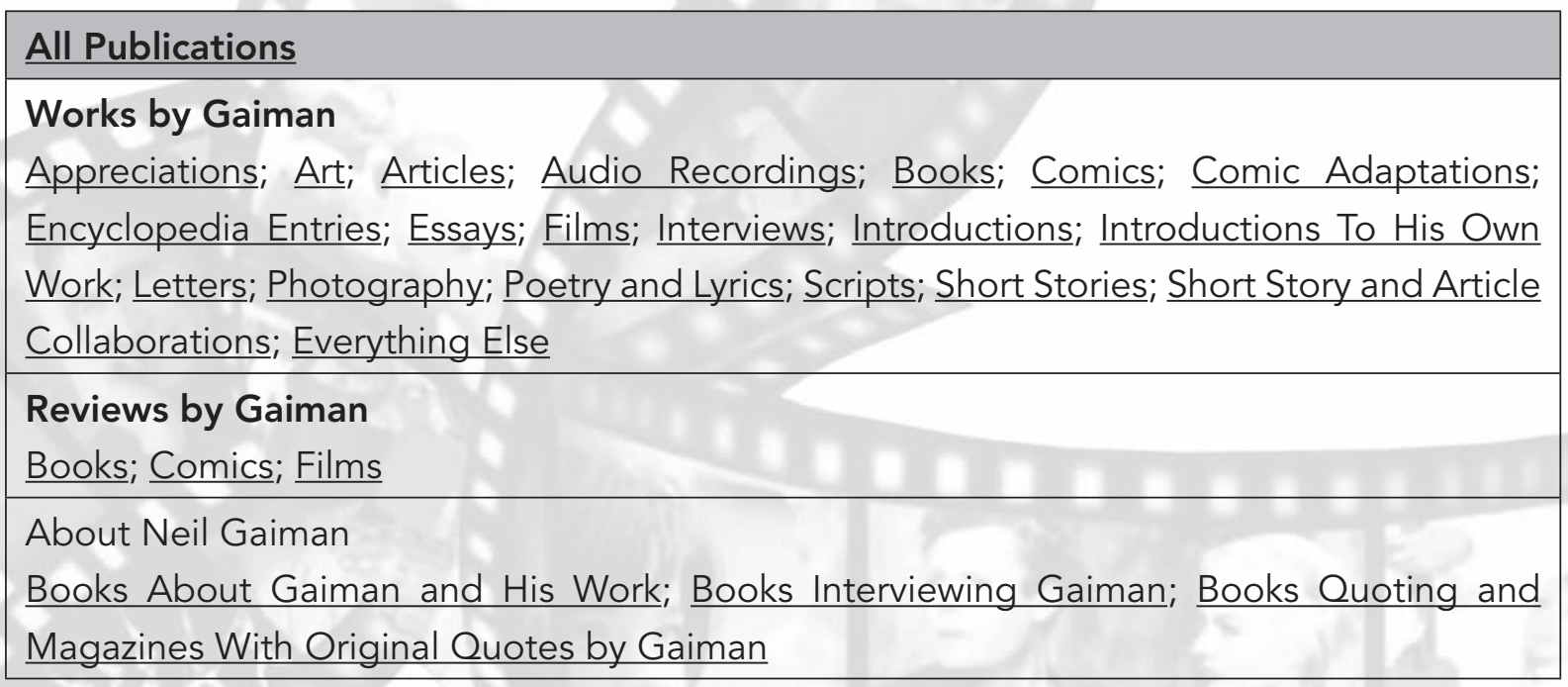




\section{DE OFICIO ESCRITOR}

En homenaje a su perfil de Twitter @neilhimself, donde demuestra que es un contador de historias adecuado al tiempo que le ha tocado vivir, queremos recordar que la profesión de Gaiman es la de escritor, o como bien planteaba David Caro (2003), de cuentacuentos. Aunque sus personajes e historias ya han conseguido una representación iconográfica a través de las ilustraciones o fotogramas (Romero Jódar, 2012), todo parte de la imaginación del autor, que plasma en distintos textos. Gaiman ha demostrado ser un narrador extraordinario, que navega entre diversos medios como guionista de cómic, novelas, novelas cortas, cuentos, cuentos ilustrados, películas y series de televisión. Y en cualquiera de ellos demuestra que lo que se le da bien es contar historias. Nacido en Portchester (Inglaterra) en 1960, ha recibido los premios más prestigiosos de la literatura como el Hugo, Bram Stoker, Nebula o Eisner, entre muchos otros.

Es tal la relevancia de sus reconocimientos, que entre todos ellos podemos destacar alguna curiosidad como que es el primer autor en ganar las medallas Newbery y Carnegie, dos de las principales distinciones de la literatura infantil en inglés por el mismo trabajo, El libro del cementerio". O como cuando la historia "Sueño de una noche de verano», ilustrada por Charles Vess, en el número 19 de la serie Sandman, ganó el busto de H. P. Lovecraft como mejor narrativa breve en 1991 del World Fantasy Award; este prestigiosos galardón tuvo que modificar las bases del concursos ediciones posteriores para que ni cómics, ni novelas gráficas, ni historietas lo volvieran a ganar, generando una gran polémica el día de los premios como nos cuenta Harlan Ellison².

\section{PRESTIGIO COMO GUIONISTA DE CÓMICS}

Gaiman empezó a darse a conocer como guionista en Estados Unidos por su obra Orquídea Negra (1988) junto a Dave McKean, con el que antes ya había realizado Casos violentos (1988). Tampoco debemos olvidar que fue el encargado de continuar el trabajo de Alan Moore con guiones para Miracleman junto con Mark Buckingham.

Pero el hito principal donde su reconocimiento empezó a crecer exponencialmente fue su reinterpretación del clásico personaje de DC, Sandman. La editora Karen Berger quería empezar a explotar el potencial de los nuevos guionistas provenientes de Inglaterra encabezados por Alan Moore, generando el sello Vertigo ${ }^{3}$ y le dieron libertad en este nuevo proyecto. Sandman cuenta la historia de la personificación del dios del Sueño y su representación en las distintas culturas o representaciones, como Oneiros, Morpheus o Kai'Ckul. Lo que nació en un principio como una obra de terror, sirve como pilar central para crear una mitología fantástica propia (Espino Martín, 2002; Hume, 2013; Zanón Fernández, 2013), usando para ello referentes, relatos y reescrituras de distintas mitologías, religiones, leyendas o cuentos populares que sirven para la narración de nuestro autor. Los setenta

1 Flood, A. (2010). Neil Gaiman wins Carnegie medal, The Guardian. Recuperado de https://www. theguardian.com/books/2010/jun/24/neil-gaiman-carnegie-graveyard-book.

2 Ellison, H. (2016). Introducción, Sandman. Tomo 4: Estación de nieblas. ECC. Recuperado de: https://www.ecccomics.com/contenidos/estacion-de-nieblas-10484.aspx.

3 Las XXIII Jornadas del Cómic de Avilés homenajearon en 2018 a este sello fundamental del cómic norteamericano que ensalzó las figuras de Alan Moore, Neil Gaiman o Grant Morrison. Noticia en https://elpais.com/cultura/2018/09/17/ka boom/1537208571 878247.html. 
y cinco números de la serie se publicaron entre 1989 y 1996, ilustrada por una amplia gama de ilustradores de muy variados estilos, organizados por varios arcos argumentales o episodios sueltos, y ha recibido innumerables premios y reconocimientos durante años. Este mismo universo ha tenido obras complementarias y diversas continuaciones del propio Gaiman, como el personaje de Muerte y los Eternos, dioses de esta mitología y hermanos del protagonista; junto a obras que continúan aspectos y personajes del universo, con mayor o menor implicación de Gaiman. La construcción de este nuevo imaginario enriquece el tradicional cómic de superhéroes, con una intencionalidad artística mayor y con infinidad de referencias literarias. Marcello Serra plantea que Sandman «funciona como un espacio híbrido, donde referencias y estilos de otros campos de la expresión entran en contacto con la tradición y la memoria del cómic de superhéroes» $(2011,4)$.

Para el trigésimo aniversario de la obra se lanzaron una serie de títulos bajo una línea común denominada The Sandman Universe ${ }^{4}$, con obras como Lucifer, The Dreaming, House of Whispers y Books of Magic. Con la línea The Sandman Universe podemos vislumbrar esa idea del Sello Gaiman, que ya hemos anticipado. Entre estas historias complementarias tenemos que hablar de la primera obra relacionada con Sandman, que deja el medio del cómic para ser una antología de cuentos infantiles: The Sandman. El libro de los sueños, editado por Neil Gaiman y Ed Kramer en 1996 y que cuenta con nombres como Caitlín R. Kiernan, Clive Barker, Gene Wolfe, Barbara Hambly o Tori Amos. La configuración de un espacio transmedia de autor ya está en marcha y este personaje eterno dará mucho que hablar.

\section{Y LLEGÓ LA TELEVISIÓN}

La primera aproximación de Gaiman al medio audiovisual fue a través de los guiones para la serie de televisión de la BBC Neverwhere en 1996. Posteriormente, convirtió esa historia en una novela, pudiendo explicar mejor aspectos de la historia que no se habían podido desarrollar en la serie. ${ }^{5}$ En 2015, pudo reeditar una nueva versión de la novela con todo lo que le hubiera gustado incluir antes (Zinnatullina, Zueva y Popp, 2018). La historia de Neverwhere es uno de los ejemplos clarísimos de la narrativa transmedia de Gaiman, ya que en 2005 se adaptó al cómic por Mike Carey y Glenn Fabry, ampliando esa visión de un Londres gótico (Meteling, 2017). Posteriormente, esta obra además ha tenido diversos proyectos para su adaptación al cine o una nueva serie de televisión, y en 2013 sí encontramos una radionovela en Radio 4 de la $\mathrm{BBC}^{6}$ con un reparto de cine (James McAvoy, Natalie Dormer, Anthony Head, Benedict Cumberbatch, Christopher Lee y el propio Neil Gaiman); de esta adaptación radiofónica se hizo un tráiler que produjo gran confusión entre muchos de los aficionados pensando en una posible película?. Ya hemos trabajado sobre la transmedialización de los tráileres, o en este caso, booktrailer, sobre todo para relatos fantásticos (Rovira-Collado, 2016).

Con Neverwhere podríamos definir el inicio de Neil Gaiman como una marca transmedia, con historias que se interrelacionan en diversos medios, novelas, relatos cortos, diseño de

4 Noticia sobre el lanzamiento en https://www.lacasadeel.net/2018/03/nuevas-historias-the-sandman.html.

5 Sobre esta adaptación ver: https://elantrodelosvampirosyotrosmonstruos.blogspot.com/2016/02/ neverwhere-de-neil-gaiman-una-puerta-la.html.

6 Disponible en https://www.bbc.co.uk/programmes/b01r522y/clips.

7 Tráiler de la radionovela Neverwhere BBCC 2014: https://www.youtube.com/watch?v=IfBaC-O0amY. 

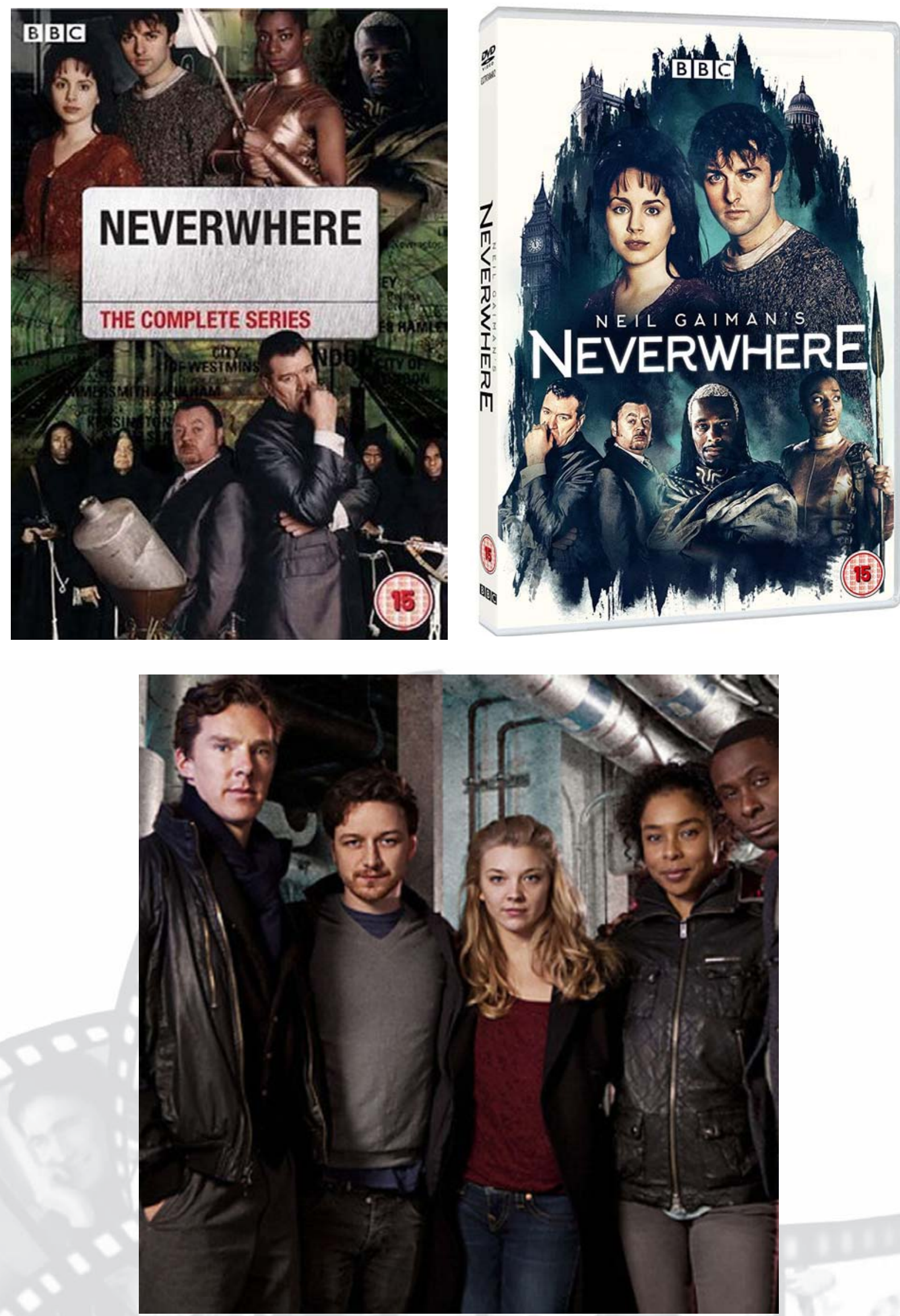
Aproximaciones ACA-FAN al universo transmedia de Neil Gaiman: creación y desarrollo de un sello propio

personajes, adaptaciones al cómic, radionovelas de sus obras, guiones para cine o series de televisión. A Gaiman ya se le reconoce no solo como guionista de cómic, sino por ser un narrador de historias en cualquier tipo de medio.

\section{UN GRAN AUGURIO TRANSMEDIA}

Antes de Neverwhere, encontramos otra importante propuesta literaria. Buenos presagios (Good Omens) fue la primera novela de Gaiman, escrita en 1990 junto con otro de los grandes nombres de la fantasía, Terry Pratchett, autor de la saga Mundodisco entre otras muchas. Casi desde su publicación la novela recibió distintas propuestas para ser adaptada al cine o la televisión, e incluso se empezó a trabajar en una segunda novela; aunque cuando Terry Pratchett murió en 2015, Gaiman decidió dejar de trabajar en la adaptación por respeto a su amigo. Pero pronto Gaiman recibió un mensaje a modo de herencia, en el que Pratchett le pedía que terminara todos los proyectos que habían iniciado juntos, por lo que la adaptación pasó a ser una prioridad, a la que en 2017 Amazon dio luz verde ${ }^{8}$. Incluso encontramos la participación del autor en la serie, con un pequeño cameo, junto con un homenaje a Terry Pratchett a través de la presencia de su genuino sombrero?.

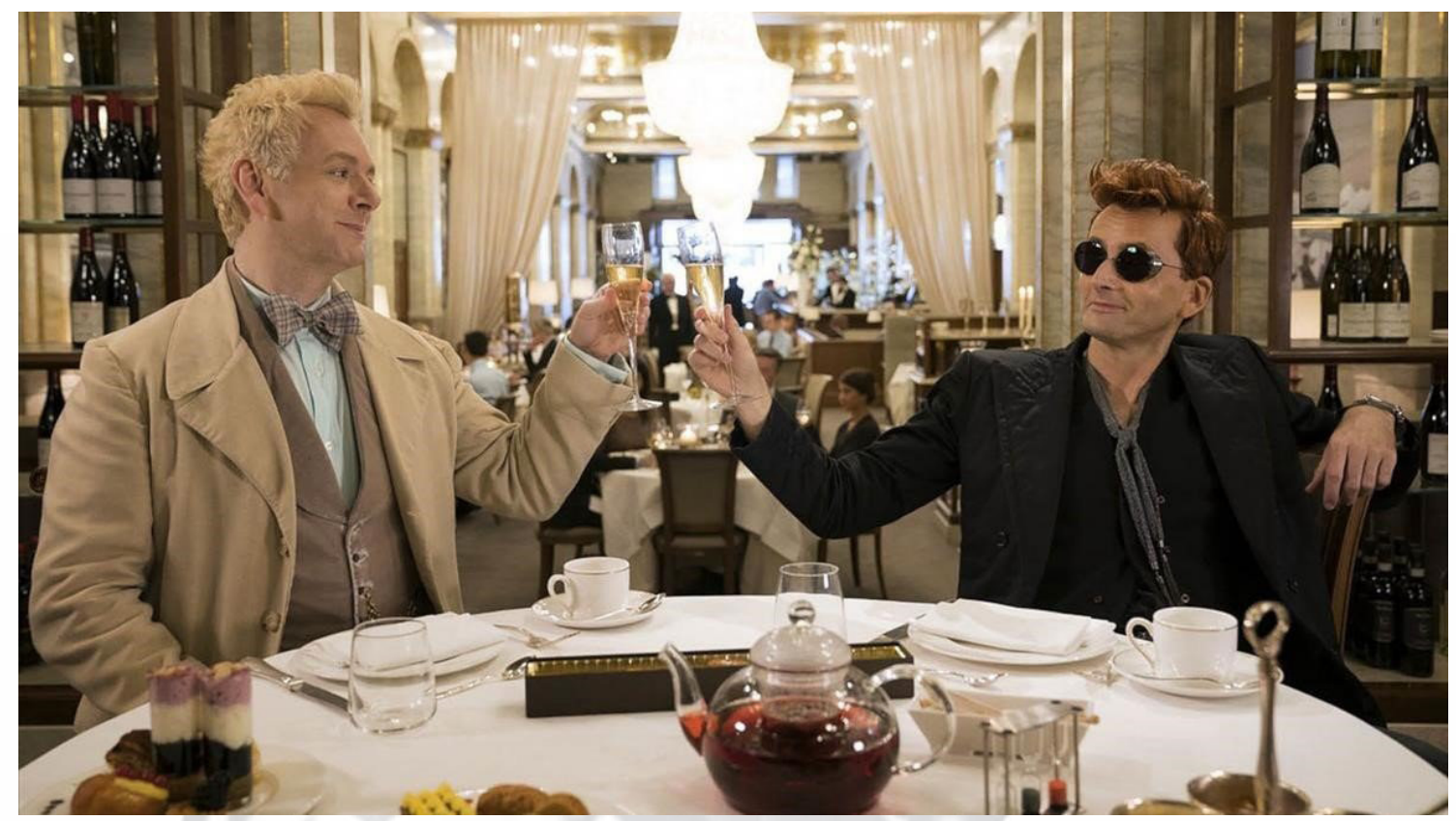

Figura 3: Fotograma de Good Omens David Tennant, Michael Sheen. (Amazon, 2019)

Extrañamente con todo lo relacionado con la obra de Gaiman, todavía no hay adaptación al cómic de esta historia, pero disponemos de otra adaptación a radionovela en la BBC 4 en 2014, que también incluye diversas ilustraciones y viñetas de autores como Sean Phillips o Simon Gurr ${ }^{10}$.

8 Noticia en Fotogramas sobre el estreno de la serie en Amazon (2019): https://www.fotogramas.es/ series-tv-noticias/a26342441/good-omens-trailer-sinopsis-reparto-estreno-neil-gaiman-amazon/.

9 Noticia sobre este cameo y el homenaje a Pratchett en Radiotimes: https://www.radiotimes.com/ news/on-demand/2020-02-05/neil-gaiman-has-the-perfect-cameo-in-good-omens-with-a-special-place-for-terrypratchetts-hat/.

10 Disponible en https://www.bbc.co.uk/programmes/b04knt4h. 


\section{UNA MITOLOGÍA AMERICANA}

En 2001, Gaiman publicó su novela más aclamada, American Gods, adaptada como serie de televisión en 2017 por Bryan Fuller y Michael Green para Starz y lanzada en España por Amazon Prime, después de diversos proyectos previos. Ya ha presentado su segunda temporada y en principio están planteadas cinco temporadas (Rovira, 2017).

La novela cosechó diversos premios como Hugo, Nebula, Locus o Bram Stoker, demostrando que Gaiman no era un simple guionista de cómics, sino un escritor fantástico (Pérez Amezcua, 2019). En 2011 se reeditó la obra con una ampliación de más de doce mil palabras.
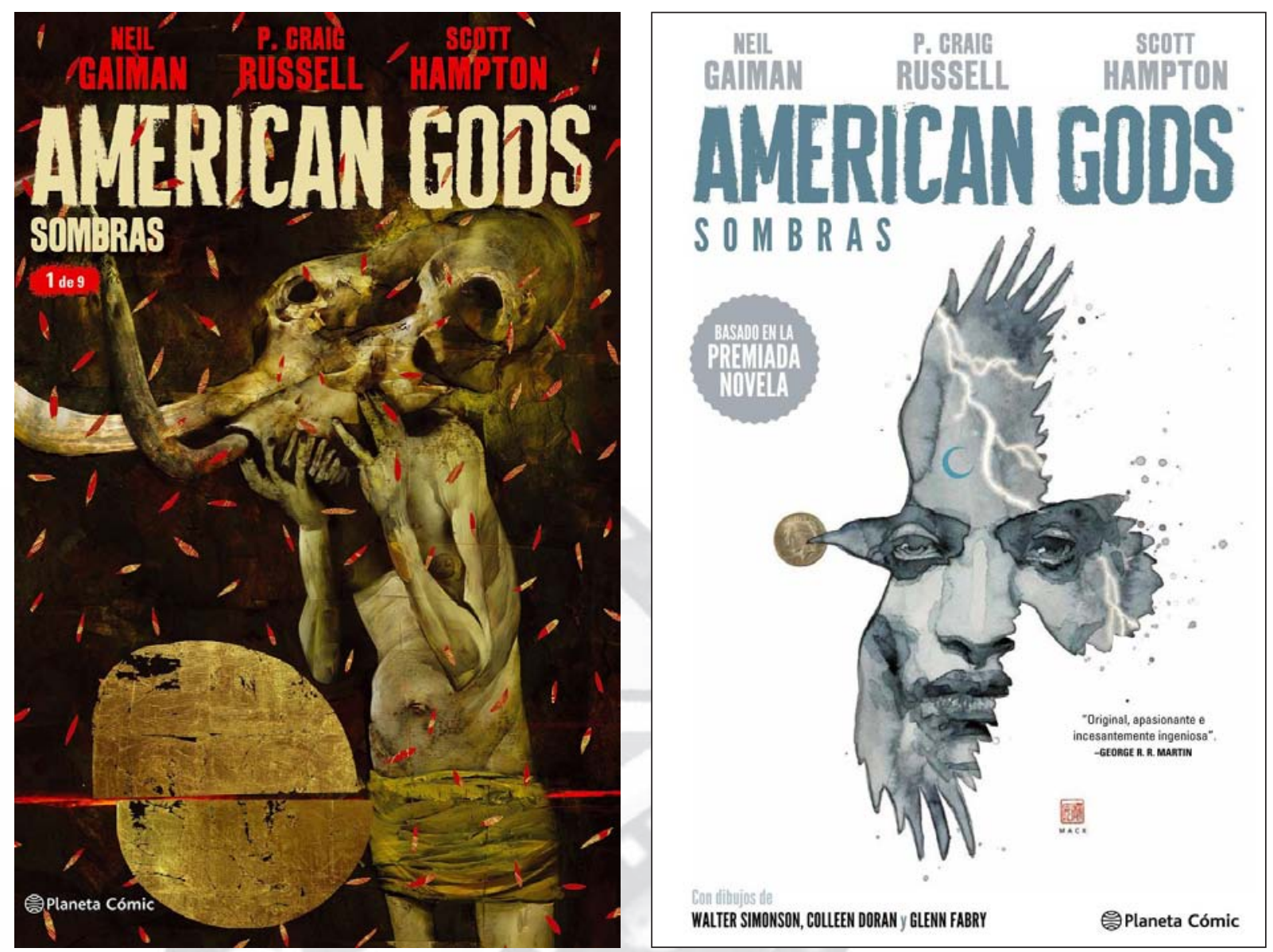

Esta adaptación televisiva tiene previsto recoger también elementos de la otra novela hermana Los hijos de Anansi, escrita en 2005. Gaiman también ha colaborado como guionista, productor ejecutivo y a partir de la segunda temporada como co-showrunner, asumiendo las funciones de productor ejecutivo y guionista junto con Jesse Alexander con la retirada de Fuller y Green, y también está trabajando con Charles H. Eglee en la tercera temporada ${ }^{11}$.

También encontramos una adaptación al cómic: American Gods: Shadows, en la editorial Dark Horse en 2017², siendo la adaptación del texto a guion, con bocetos de P.

11 Sobre la renovación de showrunner: https://fueradeseries.com/american-gods-temporada-3-renovacionshowrunner-2a7bfe6c153e.

12 Reseña de la edición española en http://www.eslahoradelastortas.com/american-gods-sombras/. 
Craig Russell y dibujos de Scott Hampton, junto con colaboraciones como Walter Simonson, Colleen Doran y Glenn Fabry. La adaptación al cómic es mucho más literal a diferencia de la serie de televisión, que en ocasiones cambia la cronología de los hechos y los ritmos a un formato televisivo.

Esta adaptación de American Gods nos permite observar el auge de las series de televisión con respecto a Neverwhere: un presupuesto mucho mayor, una producción más cuidada y en donde parece que las historias de Gaiman tienen un mayor recorrido, como también vemos en la citada adaptación de Buenos presagios, en 2019. El escritor se convierte en productor, actor y guionista de televisión.

Con la obra de Gaiman está ocurriendo un fenómeno muy interesante. Mientras que la industria del cine busca cada vez más historias basadas en cómic, los libros de Gaiman suelen adaptarse siempre a cómic; seguramente por la legión de fans que Gaiman tiene por Sandman, que aseguran la buena acogida de cada una de estas obras.

\section{EXPANSIÓN DEL SELLO GAIMAN}

El escritor o guionista de cómics entra de lleno en la industria del espectáculo y con las nuevas plataformas digitales amplía sus actividades. Y la participación de Gaiman en cualquier proyecto ya se va convirtiendo en un sello de calidad.

No podemos olvidar su participación e influencia en otras series de televisión, por ejemplo, la exitosa serie de Lucifer que comenzó en 2016 en Fox y luego pasó a Netflix. Como ya hemos mencionado tiene su paternidad en el personaje que introdujo Gaiman en la serie Sandman y que posteriormente desarrolló Mike Carey en la serie propia con Scott Hampton como primer dibujante, al que continuaron otros autores dentro de la esfera de Gaiman.

Recordemos que Mike Carey fue el encargado de adaptar el libro de Neverwhere a cómic y Scott Hampton es el dibujante principal de la adaptación al cómic de American Gods. Aunque poco tiene que ver la serie de televisión Lucifer con lo desarrollado por ambos guionistas, podemos comentar que Neil Gaiman fue el encargado de poner la voz a «Dios» en el capítulo «Once Upon a Time» de la tercera temporada en 2018.

También encontramos su sello en otras series, como en sus inicios como guionista del capítulo 8 de la quinta temporada de Babylon 5 «Day of the Dead» en 1998.

Pero, sobre todo, Gaiman ha sido guionista de dos capítulos acreditados de Doctor Who: «The Doctorss Wife» en 2011, que ganó el premio Ray Bradbury a la mejor representación dramática corta dentro de los premios Hugo (2013), y "Nightmare in Silver» en 2013; junto con otro capítulo no acreditado, «Rain Gods» en 2013; pudiendo considerarse un gran reconocimiento para cualquier autor inglés de literatura fantástica.

También se estrenó recientemente Historias probables de Neil Gaiman (Likely Stories) adaptando cuatro relatos del autor en 2016. La sinopsis de la serie -«ambientadas en Londres, estas cuatro historias están caracterizadas por ser oscuras y tenebrosas [...]. El espectador viaja así a un mundo donde se mezcla la fantasía y la realidad y acompañará a los protagonistas en su curioso y extraño viaje» ${ }^{13}$ - nos muestra que ya el autor ha generado su propio sello de identidad. Como curiosidad podemos destacar que Neil Gaiman aparece en cada uno de los episodios con guiños a su propia obra.

13 Sinopsis de la serie: http://www.sensacine.com/series/serie-19942/. 
Si se trata de apariciones en series de televisión y su relevancia transmedia, Gaiman también apareció en la popular serie The Big Bang Theory en el episodio 21 de la temporada 11, en 2018, como él mismo. Pero seguramente su participación más popular fueron sus apariciones en Los Simpson: en 2011 como él mismo en «The Book Job», y en 2017 dando voz al personaje de Snowball en el capítulo «V Treehouse of Horror XXVIII» acreditado como Nails Ghoulman ${ }^{14}$.

Y no podemos dejar de mencionar su aparición y participación en distintos documentales y cortos sobre sus obras o como referente en el mundo de la fantasía y el terror sobre otros autores, especialmente A Short Film about John Bolton (2003) ${ }^{15}$ que escribe y dirige; Statuesque (2009), corto que también escribe y dirige; la entrevista en Lovecraft: Fear of the Unknown (2008); o Temple of Art (2015) de Allan Amato y Olga Nunes, del que es también productor ejecutivo.

\section{NAVEGANDO DESDE EL OCÉANO DEL CÓMIC HASTA EL CAMINO DEL CINE Y LA TELEVISIÓN}

Pero en ese océano multiplataforma, al final del camino encontramos el cine y sus relaciones transmedia en la obra de Gaiman, donde se establecen mil vínculos intertextuales que demuestran la relevancia de nuestro autor en los últimos veinte años y se van planteando distintas posibilidades para ampliar este enorme universo creativo.

El propio autor ya nos expresó en cierta manera su relación con Hollywood en el relato «El estanque de los peces de colores y otras historias», recopilado en el libro Humo y espejos (1999, 63-90); en donde un escritor inglés llega a Los Ángeles para trabajar como guionista. No olvidemos citar la referencia directa al álbum ilustrado El día que cambié a mi papá por dos peces de colores (1997), de Gaiman, con ilustraciones de Dave McKean.

Encontramos a Gaiman en muchas producciones, aunque sea de forma tangencial. Por ejemplo, participó como guionista de uno de los primeros números de la serie Spawn (n. ${ }^{\circ}$ 9 , 1993) de Todd McFarlane, co-creando personajes como Cagliostro, Angela y Medieval Spawn. Además, hizo el guion de una miniserie protagonizada por Ángela y dibujada por Greg Capullo. En la película Spawn, de 1997, Ángela hizo un pequeño cameo, y Cagliostro tuvo un papel relevante, pero no se acredita a Gaiman como co-creador de estos personajes, como tampoco en otras producciones derivadas como el videojuego.

Pero, sobre todo, debemos de recordar los diversos conflictos legales que han arrastrado sobre la propiedad de estos personajes Neil Gaiman y Todd McFarlane y que incluyen también los derechos de Miracleman. Ángela terminó en 2013 en el Universo Marvel (Baile López, Ortiz Hernández, Rovira-Collado y Vidal Martín-Toledano, 2015) como una hermana perdida de Thor, y Neil Gaiman colaboró en el guion junto con Brian Michael Bendis en su participación en Los Guardianes de la Galaxía... ¿Podría Ángela aparecer en el Universo Cinemático de Marvel (MCU)?

La colaboración de Gaiman con el Universo Marvel incluyó en 2007 una nueva miniserie con dibujo de John Romita Jr. sobre Los Eternos creados por Jack Kirby en 1976, de la que existe una adaptación como versión audiovisual en $2014^{16}$. En la próxima fase del MCU está

14 Ficha del capítulo disponible en https://www.imdb.com/title/tt6890620/?ref =nm flmg act 6.

15 Ficha del corto disponible en https://www.imdb.com/title/tt0420181/.

16 Tráiler de esa adaptación del cómic: https://www.youtube.com/watch?v=ti9tFOUYjk0. 
prevista una película de los Eternos en 2021. ¿Cuánto veremos de esta serie en la nueva película?

También escribió en 2003 los guiones de 1602 con dibujos de Andy Kubert y portadas de Scott McKowen, donde Gaiman plantea un universo Marvel alternativo, cuatrocientos años antes del que conocemos, con la representación de los personajes clásicos en esta nueva situación y ambientada entre Inglaterra y el Nuevo Mundo. De esta serie se ha hecho una continuación con Ángela como protagonista, pero sin la participación de Gaiman, y está entre las opciones de desarrollo para la nueva plataforma digital de Disney+. Precisamente sobre esta posible serie y el martillo de Thor son las conversaciones que se producen en el citado cameo de Gaiman en The Big Bang Theory.

Además de sus propias creaciones y aportaciones, Neil Gaiman ha sido una clara influencia para otros creadores. Eric Kripke siempre ha reconocido la influencia de Sandman o de American Gods en su serie Supernatural (2005), no en vano uno de los proyectos que se plantearon para adaptar Sandman al cine fue con Eric Kripke. Kevin Smith no pudo más que incluir en sus agradecimientos a Gaiman en su película Dogma (1999) por su influencia, pero además la colaboración con Kevin Smith se amplió en la película de animación Jay and Silent Bob's Super Groovy Cartoon Movie (2013) $)^{17}$ donde le reservaron un papel a Neil Gaiman dando voz a Albert the Manservant, como parodia de Alfred Pennyworth.

Un aspecto polémico y bastante discutido es la influencia de Timothy Hunter, protagonista de Los libros de la magia (1988), en el personaje de Harry Potter. Esta es una miniserie editada por Vertigo con guion de Gaiman y dibujantes como John Bolton, Scott Hampton, Charles Vess y Paul Johnson. Cuando se publicó Harry Potter en 1997 y sobre todo con la divulgación de su imagen en el cine, muchos se acordaron de Tim Hunter, por esa imagen de joven tímido con grandes gafas redondas, pelo oscuro desaliñado, acompañado de una lechuza y que tiene el potencial de convertirse en el mago más poderoso del mundo. Aunque se intentó incluir a Gaiman en algunas de las campañas de acusación de plagio contra J.K. Rowling, nuestro autor siempre ha aclarado que las cosas que realmente tienen en común son obvias y superficiales, y que en todo caso los dos estarían homenajeando a T. H. White y su serie de novelas El rey que fue y será (The Once and Future King) ${ }^{18}$, publicada entre 1938 y 1940.

\section{GAIMAN Y EL CINE}

Más allá de las anécdotas citadas, los personajes creados y las adaptaciones entre distintos formatos, vamos a analizar una serie de películas ${ }^{19}$ donde la participación de Gaiman ha sido muy relevante.

\subsection{La princesa Mononoke (1997)}

Aunque esta fue la película del estudio Ghibli que dio a conocer en 1997 a Hayao Miyazaki en Estados Unidos, pocos saben que la adaptación del guion al inglés fue de Neil Gaiman. Esto era algo no muy conocido, ya que Miramax eliminó su nombre de los títulos de

17 Tráiler disponible en https://www.youtube.com/watch?v=la017NRDjyM.

18 Sobre la comparación de ambas obras, consultar: https://lacovacha.mx/covachos/opinion-harry-pottery-las-comparaciones-con-books-of-magicl.

19 Partimos de la selección recogida en https://www.filmmelier.com/es/mx/list/neil-gaiman-sus-historiasen-el-cine. 
crédito, hasta que Gaiman explicó su versión a través de su cuenta de Twitter. Disney quería participar del éxito de la película y encargó a su filial Miramax la distribución en el mercado occidental, apostando por una gran cantidad de nombres reconocidos para las voces de los personajes, y propusieron a Quentin Tarantino la adaptación del guion. Como él no pudo realizarla, propuso el nombre de Neil Gaiman. Entre las distintas desavenencias entre el estudio Ghibli y Miramax sobre el proceso de adaptación, Miyazaki exigió que eliminaran a algunos ejecutivos de la empresa norteamericana del póster y créditos y entre los nombres decidieron que el de Neil Gaiman era el más prescindible ${ }^{20}$.

Debemos tener en cuenta que, en España, como en gran parte del mercado occidental, las primeras traducciones audiovisuales provienen de las versiones norteamericanas y no de los originales japoneses, por lo que la versión que nos llegó era la traducción del trabajo de Gaiman.

Para esta traducción Gaiman realizó un importante trabajo de investigación. El objetivo era familiarizarse con la cultura y el folclore japonés, destacando el interés que le produjo la fábula titulada La zorra, el monje y el Mikado de los Sueños de Todas las Noches.

Esta historia encaja perfectamente en el universo de Sandman, y cuando se le pidió una nueva historia para conmemorar el décimo aniversario, Gaiman escribió un cuento con ilustraciones de Yoshitaka Amano titulado "Los Cazadores de Sueños» (1999). En un principio parecía que quería aprovechar este cuento, pero en el epílogo de la obra, él mismo reconoce que en realidad era una historia que, si bien estaba profundamente influida por cuentos y leyendas tradicionales japoneses, era una creación propia ${ }^{21}$. Pero esta historia y la influencia de la cultura japonesa no quedó aquí: para el vigésimo aniversario del dios del Sueño se decidió recuperar la historia para adaptarla a cómic por P. C. Russell (2008) en una nueva versión ilustrada de cuatro tomos.

\subsection{La máscara de cristal (2005)}

La primera película con un trabajo directo de Gaiman fue La máscara de cristal (Mirrormask), largometraje de 2005 dirigido por Dave McKean y con guion de los dos y producida por la mítica productora de Jim Henson.

Estos dos artistas se relacionan constantemente como ya hemos visto, ya sea por las colaboraciones en cómics, cuentos ilustrados o relatos como Coraline; y antes de esta película ya habían preparado un corto en 2002 basado en el cómic de ambos Signal to Noise (1989), planteado como piloto de la película que nunca pudieron realizar.

Pese a toda la trayectoria conjunta de los autores, esta película no está basada en ningún cómic, ni hay ninguna adaptación posterior al cómic, pero podemos destacar la influencia de todos los mundos e historias conjuntas de ambos autores. Lo que sí se realizó es un libro infantil ilustrado, escrito por Gaiman y con las ilustraciones de McKean, y un libro titulado La alquimia de Mirrormask (2005) con el guion gráfico, el guion completo, fotografías y textos de archivos de ambos autores, configurando un diario similar al que la protagonista usa como ayuda en la película.

20 Sobre este episodio, podemos consultar https://www.tonica.la/lux/Quentin-Tarantino-recomendo-aNeil-Gaiman-para-adaptar-La-Princesa-Mononoke-20190813-0014.html https://hipertextual.com/2019/08/neilgaiman-princesa-mononoke-creditos.

21 Sobre la creación de este relato, podemos consultar http://revistacultural.ecosdeasia.com/neil-gaimanyoshitaka-amano-y-los-cuentos-de-hadas-del-japon/. 

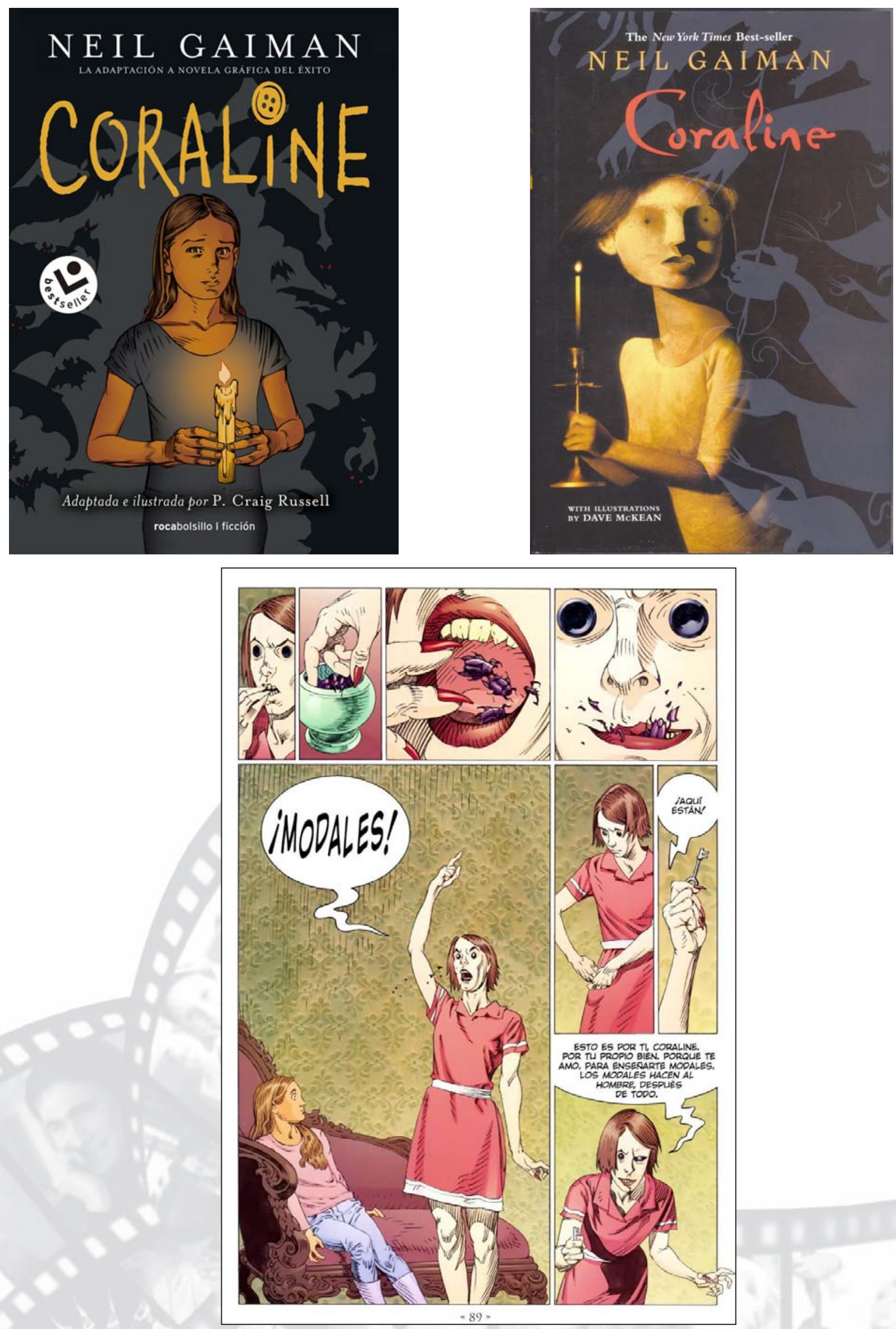
Otra de las colaboraciones entre Neil Gaiman y Dave McKean que no queremos dejar de comentar es el libro infantil Los lobos de la pared (2003), que fue adaptado a corto de animación de realidad virtual en $2018^{22}$. La experimentación estética y tecnológica es una constante de ambos autores y forma parte también del Sello Gaiman.

\subsection{Stardust (2007)}

Dirigida por Matthew Vaughn, y basada en la exitosa novela de Gaiman galardonada con el premio Mythopoeic Awards, Stardust nace originalmente como una obra a medio camino entre el cómic y el cuento ilustrado, con ilustraciones de Charles Vess (De Almeida y Cavalheiro, 2020). Normalmente se trata como cómic, ya que fue DC en su sello Vertigo quién lo editó en primera ocasión en 1997 en cuatro partes, y en 1998 en un tomo único. En España, Norma Editorial lo publicó en 1998. Posteriormente Gaiman adaptó la historia a novela sin ilustraciones en 1998 editado por Spike Avon Book. En España primero la publicó Norma en 2001 y Roca en 2007, ya usando la portada de la película como reclamo. También se adaptó a radionovela en 2016 por la BBC 23 . La participación de actores y actrices consagrados como Michelle Pfeiffer, Robert De Niro o Peter O'Toole demuestra el interés suscitado por esta producción británica. La fantasía de Gaiman (Casas, 2007), se llena de intertextualidad a lo largo de todo el relato, siendo un relato de aventuras con el sello del autor.

\subsection{Beowulf: la leyenda (2007)}

En esta película de animación dirigida por Robert Zemeckis, Gaiman se encargó junto con Roger Avary de adaptar el poema épico Beowulf a un guion cinematográfico. Entre los objetivos de esta adaptación se reconoce que los guionistas querían realizar su propia interpretación de las motivaciones de Grendel, y también qué sucede cuando Beowulf estaba en la cueva de la madre de Grendel, alegando que Beowulf no es un narrador fiable en esa parte del poema, ayudando a conectar los distintos actos. De esta versión y basado en su guion, Chris Ryall y Gabriel Rodríguez se encargaron de realizar el cómic oficial de la película. Manuel Barrero (2007) hace una completa reseña de la película y su cómic, además de otras adaptaciones del poema al cómic de mayor o menor éxito a lo largo de los años. Sin embargo, la más reciente y aclamada en nuestro país es la versión de Santiago García y David Rubín, publicada por Astiberri en 2013. Esta versión hispana fue nominada a mejor adaptación desde otro medio en los Premios Eisner de 2018 y posiblemente también deba parte de su interés a la reinterpretación previa del mito por parte de Avary y Gaiman. Es indiscutible la relevancia de este poema anglosajón, localizado entre los siglos VIII y X como texto heroico canónico y casi fundacional de la literatura inglesa, pero la visión de Gaiman ha permitido traerlo al siglo XXI, además de generar otras obras como la novela de Caitlín R. Kiernan (2007) también basada en el guion de Gaiman y Avary (Conde Silvestre, 2009).

22 Este corto fue estrenado en el Festival de Sundance de 2018, como se recoge en https://www. elisayuste.com/lij-gran-pantalla-rv/.

23 Accesible en https://www.bbc.co.uk/programmes/b07xs1fd 


\subsection{Los mundos de Coraline (2009)}

Dirigida por Henry Selick, es seguramente el mayor éxito relacionado con Gaiman y el cine. Se trata de una de sus novelas más conocidas junto con American Gods, y su nombre se dio a conocer a un público mayoritario por esta adaptación. La novela fue publicada en 2002, obteniendo los premios Hugo, Nebula a mejor novela corta y Bram Stoker a la mejor novela para jóvenes lectores, y cuenta con las ilustraciones de Dave McKean, reforzando esa relación ya citada. En 2008 se publicó una adaptación al cómic realizada por P. Craig Rusell, donde adapta a su propio estilo y narrativa la obra, pero se mantiene muy fielmente el texto de la novela. Sin embargo, las ilustraciones permiten nuevas interpretaciones, como la distinta edad que aparenta la protagonista de esta historia de terror.

La película fue un gran éxito de público y crítica, incluidos premios y nominaciones a los Globos de Oro y los Oscar, pero existen varias diferencias entre ellas: la más comentada es el personaje de Wybourne, amigo de la protagonista que en la novela es solo mencionado como vecino, y que aquí tiene una gran importancia sustituyendo en muchas ocasiones el protagonismo del gato en la novela. Aunque la trama varía y existen otras diferencias como la utilización de la muñeca para espiar a los niños, la esencia de la obra se mantiene y estamos viendo realmente la misma historia con otros elementos.

Además de estas tres obras, en 2009 también se realizó un musical ${ }^{24}$ de David Greenspan y Stephin Merritt y un videojuego (Papaya Studio) basado directamente en la iconografía de la película.

Nos encontramos ante una clara propuesta transmedia, donde una misma historia creada en 2002 se adapta perfectamente a cinco medios distintos y que recogen la personalidad de cada uno de sus creadores, pero que todas mantienen el «Sello Gaiman».

\subsection{Cómo enamorar a una chica punk (2018)}

Dirigida por John Cameron Mitchell, es la última película estrenada de la que hablaremos, que adapta el relato corto de Gaiman «Cómo hablar con las chicas en las fiestas» («How to Talk to Girls at Parties») que se publicó dentro del libro Objetos frágiles (Fragile Things), en 2006 y que recibió el premio Locus. Antes de esta versión cinematográfica existe una adaptación al cómic en 2016 con los dibujos de Gabriel Bá y Fábio Moon, que hacen un trabajo excepcional para dibujar la historia, y que funciona igual de bien como literatura o narrativa gráfica.

Lo que en el breve relato y en el cómic muestra una breve historia de dos chicos que se confunden de fiesta y encuentran un montón de chicas que no terminan de entender, con breves referencias al punk, partiendo de los propios gustos adolescentes del escritor, en la película se convierte en un elemento central de la trama como reivindicación del género, aunque se trate de un punk algo edulcorado, hasta convertirse en una comedia romántica con dos amantes que vienen de muy diferentes mundos. El guion de la película es de Philippa Goslett y del propio director John Cameron Mitchell, y cuenta con la participación de Alex Sharp, Elle Fanning y Nicole Kidman entre sus actores y actrices.

24 Reseña del musical Coraline (2009): http://blogs.slj.com/afuse8production/2009/05/21/coraline-themusical-a-theatrical-revuereview/. 


\section{BUENOS PRESAGIOS PARA EL FUTURO DEL SELLO}

Hemos visto que cualquiera de las historias de Neil Gaiman en cualquiera de sus medios puede dar el salto a otros medios diversos, de cómics a series, relatos a películas, novelas a series; y de una manera muy recurrente cualquier creación podrá ser un cómic, donde las legiones de fans que cultivó en este medio aseguran una buena acogida. Este ha sido un análisis de académicos aficionados a su obra, que cuenta con millones de seguidores de todo el mundo.

Neil Gaiman llegó a ser descrito por la revista Forbes como «el autor de best sellers del que no has oído hablar nunca» ${ }^{25}$ y esto se ha ido modificando de diferente manera como por ejemplo: «el escritor más famoso del que nunca se ha oído hablar» ${ }^{26}$, y en cierta manera parecía cierto. Gaiman contaba con una legión de fans, pero era desconocido para una gran parte del público que sí conocía su obra. Sus primeros pasos en el cine hicieron que empezara a ser más conocido, pero éxitos como Coraline quedan más en la fama de su director que en el autor de la obra, aunque después muchas de sus obras vengan acompañadas de «del autor de Coraline», por el éxito comercial que tuvo.

Sin embargo, tal como demuestra el éxito de las últimas adaptaciones televisivas, las posibilidades transmedia del autor lo han convertido en una apuesta segura en estos momentos. Por ejemplo, sobre el libro Mitos nórdicos (Norse Mythology), publicado en 2017, uno de sus últimos éxitos, ya se ha anunciado su adaptación al cómic ${ }^{27}$ en dieciocho números con la participación otra vez de P. Craig Russell, junto con ilustraciones de Mike Mignola y Jerry Ordway entre otros. Esta nueva reinterpretación mitológica demuestra la capacidad de Gaiman para generar nuevos relatos a través de un completo proceso de documentación (Vilar Oliveira, 2017, 192-194)... ¿Veremos en un futuro una serie o película, de esta nueva narración de los clásicos dioses nórdicos?

Pero existen dos grandes proyectos cinematográficos en distinto proceso de adaptación. En primer lugar, la adaptación cinematográfica del libro infantil El libro del cementerio, publicado en 2008, con ilustraciones nuevamente de Dave McKean en la versión original y por Chris Riddell en su edición en españo| ${ }^{28}$. En 2014, fue adaptado al cómic por P. Craig Rusell junto con distintos dibujantes como Kevin Nowlan, Tony Harris, Scott Hampton, Galen Showman, Jill Thompson y Stephen B. Scott (Chang, 2015). Desde hace años han sonado distintos proyectos de película con nombres como Neil Jordan ${ }^{29}$ como director y guionista en 2010, una posible versión animada de nuevo con Henry Selick ${ }^{30}$ a la cabeza, aunque también se barajó en 2013 el nombre de Ron Howard ${ }^{31}$ como encargado de realizarla.

En segundo lugar, la esperada adaptación de Sandman, acabando prácticamente donde comenzamos. Si este cómic es posiblemente la obra más reconocida de este escritor

25 Entrevista al autor en 2015: http://www.adriasnews.com/2014/08/neil-gaiman-entrevista.html.

26 Entrevista al autor en 2013: https://elpais.com/elpais/2013/12/12/icon/1386878728 230511.html.

27 Sobre la adaptación de Dark Horse, ver https://www.latercera.com/mouse/dark-horse-convertira-comicnorse-mythology-neil-gaiman/.

28 Reseña en https://sagacomic.blogspot.com/2010/01/el-libro-del-cementerio 14.html.

29 Noticia de 2010: http://www.comicdigital.com/2492 1-El Libro del Cementerio de Neil Gaiman tendra su propia pelicula.html.

30 Noticia de 2012: https://www.defanafan.com/2012/04/henry-selick-dirigira-el-libro-del.html.

31 Noticia sobre la posible adaptación en 2013: https://www.scifiworld.es/cine/cine/el-libro-delcementerio-ron-howard-negocia. 
Aproximaciones ACA-FAN al universo transmedia de Neil Gaiman: creación y desarrollo de un sello propio

polifacético (Ortiz, 2014), podemos decir que, desde su publicación, hace más de treinta años se han oído proyectos para adaptarla al cine. Los últimos nombres que se oyeron fueron algunos como Joseph Gordon-Levitt, David S. Goyer, Jack Thorne y Eric Heisserer. Pero finalmente parece que Sandman se adaptará a serie de televisión por Netflix, que ya ha anunciado una primera temporada y en la que Neil Gaiman estará muy implicado como se puede ver en un hilo de Twitter ${ }^{32}$. En esta serie están implicados Allan Heinberg como showrunner y David S. Goyer y el propio Gaiman como productores ejecutivos. Los aficionados esperamos su estreno con muchas expectativas.
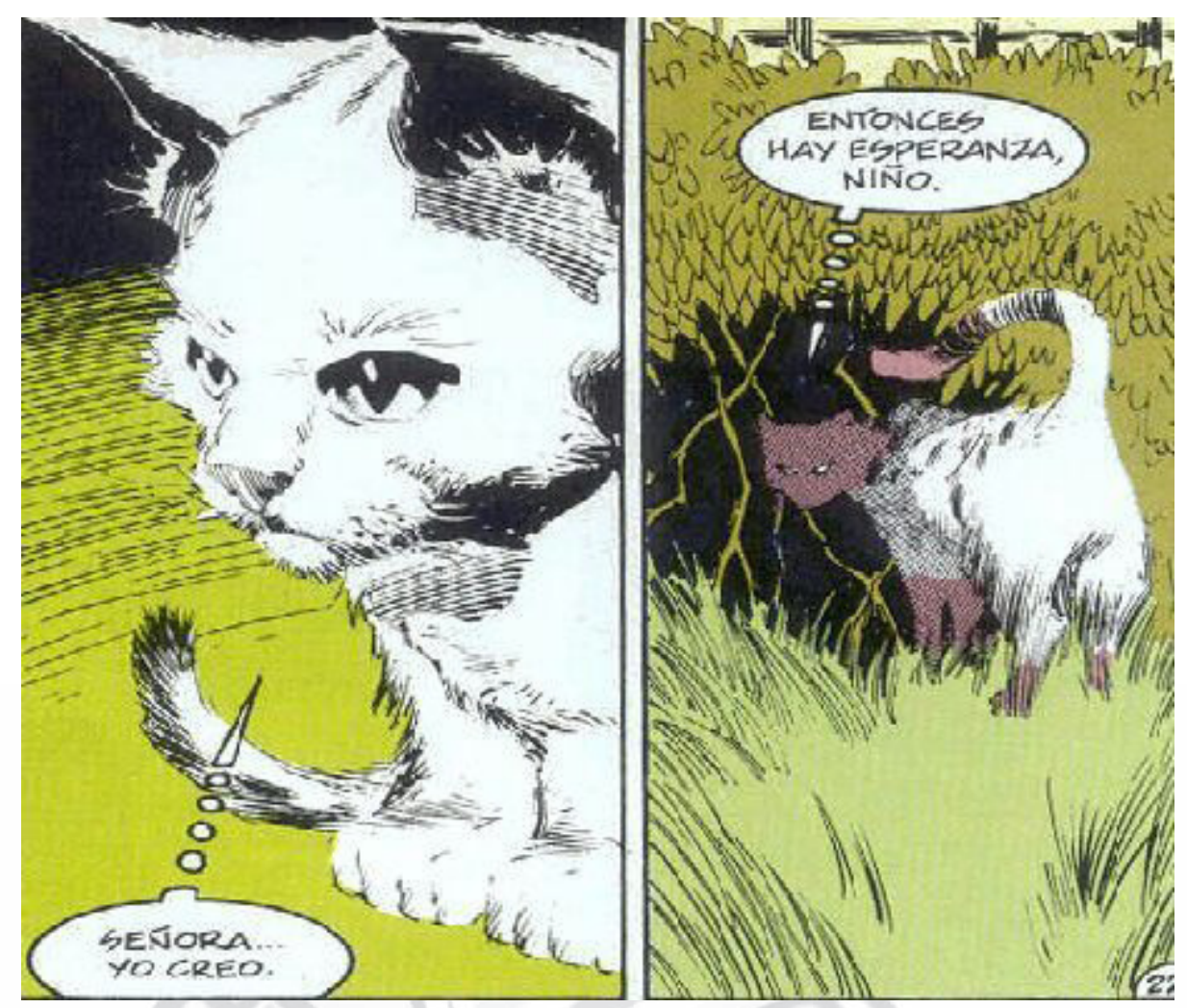

Figura 4: Ilustración Kelley Jones «A Dream of a Thousand Cats», Sandman 18, Agosto 1990

Pero mientras esperamos esta producción que seguramente sufrirá retraso por la crisis actual del Covid-1933, podemos recomendar un cortometraje basado en esta obra, titulado: Sandman: 24 Hour Diner, realizado en 2017 por los canadienses Nicholas Brown y Evan Henderson y que adaptan la historia «24 Hours» una de las primeras historias que recoge la serie Sandman $\left(n .^{\circ} 6,1989\right)$ cuando estaba más orientado al cómic de terror. La adaptación recoge perfectamente el tono violento y la estética gore que tan bien ilustró en los comics Mike Dringenberg. Esta adaptación ha recibido muy buenas críticas e incluso Neil Gaiman dio su aprobación a la misma; es decir, recibió el seal of approval ${ }^{34}$.

32 Detalles sobre esta adaptación a la televisión: https://www.lacasadeel.net/2019/07/primeros-detallesde-la-adaptacion-de-sandman-que-prepara-netflix.html.

33 El inicio de la serie estaba previsto para mayo de 2020 en el Reino Unido: https://pulpfictioncine.com/ contenido/9103/sadman-de-netflix-se-empezaria-a-grabar-en-mayo.

34 Tenemos acceso al corto en la siguiente web, que también recoge el reconocimiento del propio Gaiman: $\quad$ https://www.joblo.com/movie-news/cool-videos-sandman-fan-film-that-got-neil-gaiman-s-seal-ofapproval-267-02. 
Como hemos visto, la construcción de un Sello Gaiman va vinculada en un principio al sello Sandman. Después del éxito de la serie regular, la editorial DC y su sello Vertigo aprovecharon el éxito con el sello Sandman Presents donde se incluyeron muchas historias, spin-offs de personajes de la saga, y toda una continuación del universo de Gaiman, incluyendo éxitos como el de Lucifer hasta las últimas propuestas del trigésimo aniversario.

Ese sello Sandman ya empezaba a ser acompañado por un Sello Gaiman desde el final de la serie, como se vio en la obra Mr. Hero. The Newmatic Man (1996), obra presentada como «Neil Gaimanıs Mr Hero The Newmatic Man», creado para la editorial Tekno Comix donde Gaiman junto con otros ilustres como Leonard Nimoy aportan ideas pero que eran desarrolladas por otros autores ${ }^{35}$.

También en otras publicaciones se puede reconocer ese sello de Neil Gaiman, como en la presentación de libros y audiolibros de gusto del autor con el sello Neil Gaiman Presents ${ }^{36}$ donde esta presentación ocupa casi tanto como el título o el nombre del autor o autora.

El universo transmedia de Gaiman es enorme y abarca desde los infinitos salones del sueño y las reinterpretaciones de distintas mitologías hasta creaciones infantiles que terminan encantando a todos los públicos. El cine y las series de televisión están dando la notoriedad merecida al autor, y pronto esa presentación intertextual de nuevas obras o adaptaciones, introducida muchas veces por «Del creador de...» como reconocimiento a su obra frente a su figura, podrá ser sustituida por su propio sello, el de uno de los autores principales de la literatura fantástica en la actualidad.

\section{BIBLIOGRAFÍA}

Baile lópez, E.; Ortiz hernández, F. J.; Rovira-Collado, J. y Vidal Martín-Toledano, J. (2015), «Del cómic a la narración transmedia en la formación universitaria. Mapa transmedia de Los Vengadores». XIII Jornadas de Redes de Investigación en Docencia Universitaria. Nuevas estrategias organizativas y metodológicas en la formación universitaria para responder a la necesidad de adaptación y cambio. Alicante: Universidad de Alicante (pp. 501-513). http://rua.ua.es/dspace/handle/10045/49134 [consulta: 4 mayo 2020].

BAile LÓPEZ, E.; ROVIRA-Collado, J. y VidAL MARTín-TOledano J. (2016), «Avengers Assemble! Análisis transmediático de la saga de sagas superheroica». En Encabo, E. Urraco, M. y Martos, A. (Eds.), Sagas, distopías y transmedia: ensayos sobre ficción fantástica. León: Marcial Pons, pp. 163-174.

BARRERO, M. (2007), «El Beowulf de Gaiman». Tebeosfera. https://tebeosfera.blogspot. com/2007/11/el-beowulf-de-gaiman.html [consulta: 4 mayo 2020].

CAMPBelL, H. (2015), El arte de Neil Gaiman. Barcelona: Norma.

CARO, D. (2003), «Neil Gaiman y la cadena infinita» Tebeosfera, https://www.tebeosfera. com/1/Documento/Articulo/Guionistas/Neil/Gaiman.htm [consulta: 4 mayo 2020].

CASAS, Q. (2007), "Les fantasies de Neil Gaiman: Stardust». Benzina: Revista d'excepcions culturals, 21.

35 Sobre esta propuesta editorial: https://buffetcritico.wordpress.com/2016/06/26/un-campeon-de-vaporinmaculado-neil-gaimans-mr-hero-the-newmatic-man/.

36 En la web encontramos libros presentados bajo este lema, producidos por el propio autor: https://www.audible.com/ep/Neil Gaiman Presents. 
CONDE SilveSTRE, J. C. (2009), «Estrategias y recursos para la reelaboración de un poema heroico medieval en el siglo XXI: los beowulfs de Robert Zemeckis y Caitlín R. Kiernan». En Miscelánea Medieval Murciana, XXXIII, pp. 9-31. https://digitum.um.es/digitum/bits tream/10201/16608/1/1033114160211PB.pdf [consulta: 4 mayo 2020].

CHANG, T. Ch. (2015), «l am nobody: fantasy and identity in Neil Gaimanıs The Graveyard Book». Journal of English Studies 13, pp. 7-18.

De Almeida, R. y Cavalheiro, M. G. (2020), «O insólito em Stardust: análise intermidiática». Letras de Hoje: Estudos e debates de assuntos de lingüística, literatura e língua portuguesa, vol. 55, 1, pp. 94-106, http://dx.doi.org/10.15448/1984-7726.2020.1.33394

ESPINO MARTín, J. (2002). "La reinterpretación del mito clásico en el comic-book U.S.A. Un análisis del mito en el Sandman de Neil Gaiman y el Epicurus el Sabio de MessnerLoebs». Alvar Ezquerra, C. (coord.) El mito, los mitos, Madrid: Sociedad Española de Literatura General y Comparada, pp. 45-54.

GARCíA, J. M. (2013). «Cine y cómic. Los encuentros y desencuentros de una pareja condenada a entenderse». CuCo, Cuadernos de cómic 1, pp.195-221. http://cuadernosdecomic. com/docs/revista1/cine_comic garcia.pdf [consulta: 4 mayo 2020].

HUME, K. (2013), «Neil Gaimanıs Sandman as Mythic Romance». En Genre: Forms of Discourse and Culture, vol. 46, 3, pp. 345-365.

JeNKINS, H. (2003), "Transmedia Storytelling. Moving Characters from Books to Films to Video Games can Make them Stronger and more Compelling». MIT Technology Review https://www.technologyreview.com/news/401760/transmedia-storytelling [consulta: 4 mayo 2020].

JeNKINS, H. (2006), «Confesiones de un Aca/Fan». Fans, blogueros y videojuegos. La cultura de la colaboración. Barcelona: Paidós. pp. 3-12.

JenKINS, H. (2008), Convergence culture. La cultura de la convergencia en los medios de comunicación. Barcelona: Paidós.

KRESS, G. y VAN LeEUWEN, T. (2001), Multimodal Discourse. The Modes and Media of Contemporary Communication. Londres: Arnold.

Meteling, A. (2017), "Gothic London: On the Capital of Urban Fantasy in Neil Gaiman, China Miéville and Peter Ackroyd». Brumal. Revista de Investigación sobre lo Fantástico, vol. 5, 2, pp. 65-84. https://doi.org/10.5565/rev/brumal.416

ORTIZ, F. J. (2014), «La comicoteca, Sandman». Abandondad toda esperanza, http:// abandonadtodaesperanza.blogspot.com/2014/03/la-comicoteca-sandman-vol-3-paisde.html [consulta: 4 mayo 2020].

Pérez AmeZCUA, L. A. (2019). «Mito y mistagogía hipermoderna en American Gods». LOSADA, J. M. y LIPSCOMB (eds.), Myth and Audiovisual Creation Berlín: Logos Verlag, pp. 127138.

Red Internacional de Universidades Lectoras, (2009). «Neil Gaiman, Veinte años modelando sueños», Revista Imaginarios 1 https://issuu.com/imaginarios/docs/imaginarios01 [consulta: 4 mayo 2020].

RODRÍGUEZ FERRÁNDIZ, R. (2014). «El relato por otros medios ¿un giro transmediático?». CIC. Cuadernos de Información y Comunicación, vol. 19, pp.19-37. https://doi.org/10.5209/ rev CIYC.2014.v19.43901.

ROMERO JÓDAR, A. (2012), The iconical discourse community, the narrative iconical subgenres and the trauma graphic novel in English. [tesis doctoral] Universidad de Zaragoza. 
ROVIRA, J. M. (2017), «Qué puedes encontrar en American Gods, la novela de Neil Gaiman». Fuera de Series. Recuperado de https://fueradeseries.com/qu\%C3\%A9-puedesencontrar-en-american-gods-la-novela-de-neil-gaiman-7c80cb5f480a [consulta: 4 mayo 2020].

ROVIRA-COLLADO, J. (2016), «El booktrailer y el booktuber como estribillos transmedia de sagas fantásticas». Encabo, E. Urraco, M. y Martos, A. (eds.), Sagas, distopías y transmedia: ensayos sobre ficción fantástica, León: Marcial Pons, pp. 59-75.

ROVIRA-COLLADO, J. y BAILE-LÓPEZ, E. (2108). «Fuerza y superpoderes de los lectores en universos transmedia comerciales: libros y cómics en The Avengers y Star Wars». SEGARRASAAVEdRA, J., HidAlgo-Marí, T., Rodríguez-FerRÁndiz, R. (coords.). Actas de las Jornadas Científicas Internacionales sobre Análisis del discurso en un entorno transmedia. Alicante: Universidad de Alicante, 2018. (Colección Mundo Digital de Revista Mediterránea de Comunicación; 11), pp. 45-59 http://dx.doi.org/10.14198/MEDCOM/2017/11 cmd.

ROVIRA COLLADO, J. M. y ROVIRA-COLLADO, J. (2012) «15 anys de còmic-vinyetes a la Universitat d`Alacant: Unicòmic com a model acadèmic de didàctica i promoció de la lectura». Ítaca. Revista de Filologia 3 (2012), pp. 223-248. http://rua.ua.es/dspace/handle/10045/26853 [consulta: 4 mayo 2020].

SeRRA, M. (2011), La semiosfera de los cómics de superhéroes, [tesis doctoral], Universidad Complutense de Madrid. https://dialnet.unirioja.es/servlet/tesis?codigo $=97233$ [consulta: 4 mayo 2020].

SCOLARI, C. (2013). Narrativas transmedia. Cuando todos los medios cuentan. Barcelona: Deusto.

VILAR OliveIRA, L. (2017). "Os Mitos nórdicos segundo Neil Gaiman». Anuário de literatura: Publicaçao do Curso de Pós-Graduaçao em Letras, Literatura Brasileira e Teoria Literária, vol. 22, 1, pp. 192-196.

ZinNATUllinA, Z.R., ZUeVA, E.V., POPP, I. A. (2018), "Series de television y su novelización: Neverwhere por Neil Gaiman». Orbis: revista de Ciencias Humanas, Año 14, n. extra 41, 1, pp. 19-26.

ZANÓN FERNÁNDEZ, E. (2013), «El mito como temática superventas en el cómic de finales del siglo XX: el extraño caso de Neil Gaiman y su The Sandman». Lipscomb, A. y Losada Goya, J. M., (coord.) Mito e interdisciplinariedad: Los mitos antiguos, medievales y modernos en la literatura y las artes contemporáneas, Bari: Levante Editori, pp. 353-362. 